\title{
SYNTHESIS OF GALLIC ACID INTERCALATED Mg/Al- HYDROTALCITE BY DIRECT CO-PRECIPITATION METHOD AND ITS APPLICATION TO ADSORPTION OF Au(III)
}

\author{
I.Yanti ${ }^{1}$, S. J. Santosa ${ }^{2}$, I. Kartini ${ }^{2}$ and W. F. Winata ${ }^{3, *}$ \\ ${ }^{1}$ Department of Chemistry, Universitas Islam Indonesia, Yogyakarta, Indonesia \\ ${ }^{2}$ Department of Chemistry, Universitas Gadjah Mada, Yogyakarta, Indonesia \\ ${ }^{3}$ Department of Teknologi Pengolahan Kulit, Politeknik ATK Yogyakarta, \\ Yogyakarta, Indonesia \\ *E-mail: wahyu.fajar.w@kemenperin.go.id
}

\begin{abstract}
Intercalation of gallic acid $(\mathrm{GA})$ on $\mathrm{Mg} / \mathrm{Al}-\mathrm{HT}$ has been performed by direct co-precipitation $\operatorname{method}$ of $\mathrm{Mg}\left(\mathrm{NO}_{3}\right)_{2}$, $\mathrm{Al}\left(\mathrm{NO}_{3}\right)_{2}$ and $\mathrm{GA}$ at various molar ratios. The intercalation products of GA in $\mathrm{Mg} / \mathrm{Al}-\mathrm{HT}-\mathrm{GA}$ were characterized by infrared spectrophotometer and XRD diffractometer. The effects of molar ratio variations on the synthesis of $\mathrm{Mg} / \mathrm{Al}-$ HT-GA and adsorption capacity of Au(III) were also studied. The analysis using an infrared spectrometer and XRD diffractometer showed that GA had been intercalated in the interlayer of $\mathrm{Mg} / \mathrm{Al}-\mathrm{HT}$ with the value of $\mathrm{d}$ (basal spacing $\mathrm{d}_{003}$ ) increased with increasing of the concentration of GA. The adsorption of $\mathrm{Au}(\mathrm{III})$ by $\mathrm{Mg} / \mathrm{Al}-\mathrm{HT}-\mathrm{GA}$ synthetized was optimum at $\mathrm{pH} 10$ and variation of $\mathrm{Mg}: \mathrm{Al}: \mathrm{GA}=2: 1: 0.5$ with the adsorption capacity of $90.1 \%$.

Keywords: Intercalation, Gallic Acid, Mg/Al-Hydrotalcite, Au(III), Adsorption.
\end{abstract}

(C) RASĀYAN. All rights reserved

\section{INTRODUCTION}

Hydrotalcite (HT) is a type of clay material that is commonly used as adsorbents to adsorb organic and inorganic compounds in solution. The reason behind it is that the HT structure consists of double-layer hydroxides (Layered Double Hydroxides/LDHs) which have a layer of positively charged compounds so that it is capable to adsorb anionics. ${ }^{1,2}$ HT is commonly used for adsorption of anionic compounds in solution such as for the adsorption of sulfate, ${ }^{3,4}$ chromate $^{3}$ like $\mathrm{Cr}(\mathrm{VI}){ }^{12}$ and $\mathrm{Cr}(\mathrm{IV}),{ }^{11}$ nitrate, ${ }^{5}$ anionic dyes, ${ }^{6,13}$ gold in the form $\mathrm{AuCl}_{4}^{-7-9}$, and $\mathrm{Cu}(\mathrm{II}) .{ }^{10}$ The adsorption of $\mathrm{AuCl}_{4}{ }^{-}$or $\mathrm{Au}(\mathrm{III})$ in a solution using HT has been done by some researchers using HT for the recovery of gold in solution, however, the adsorbed $\mathrm{AuCl}_{4}{ }^{-}$has not been able to be reduced to $\mathrm{Au}(0){ }^{7}$

Modification of HT is necessary for the adsorption and reduction of $\mathrm{Au}(\mathrm{III})$ adsorbed on HT simultaneously. Those processes can be optimized by considering the multiple parameters such as the modification because of the surface and interlayer area structure of HT consists of two hydroxide layers.

The bio-adsorbents that have hydroxyl, carbonyl functional groups, etc. can be used as bio-adsorbent for metal ions such as $\mathrm{Cr}(\mathrm{VI}) .{ }^{14}$ The modification is typically made by using an organic compound which has a sizeable potential reduction, such as a derivative of phenol compounds that can reduce metal ion. ${ }^{15-21}$ Fitriani ${ }^{8}$ used the derivatives of phenol i.e. gallic acid (GA) to prepare HT-GA which was applied to the adsorption and reduction of $\mathrm{Au}(\mathrm{III})$ to $\mathrm{Au}(0)$. The results showed better adsorption and reduction activities in the modified adsorbent. Another important parameter in optimizing adsorption and reduction of $\mathrm{Au}(\mathrm{III})$ is the optimization of the area of HT through the intercalation between layers using a modifier. The intercalation between the layers by using a modifier can typically occur via (a) thermal reaction, (b) rehydration of $\mathrm{Mg} / \mathrm{Al}-\mathrm{HT}$-calcined with a solution containing anions, (c) anion exchange and (d) coprecipitation (direct synthesis) with the addition of a solution of $\mathrm{M}^{2+}$ and $\mathrm{M}^{3+}$ to the solution anion. ${ }^{22}$ The intercalation through anion exchange methods was carried out by reacting an anion solution with HT material, ${ }^{8}$ it is observed from the study that the method failed in intercalating the modifier into the interlayer of HT, however, it is only immobilized on the surface. 
The direct co-precipitation method (direct synthesis) is a direct deposition process of all metal-forming precursors of HT and modifiers simultaneously under the alkaline conditions. The research on intercalation with direct co-precipitation has shown that method can produce a greater basal spacing than the ion exchange method, ${ }^{23}$ so direct co-precipitation method is very effective for the intercalation of the compound in the interlayers of $\mathrm{Mg} / \mathrm{Al}-\mathrm{HT}$.

\section{EXPERIMENTAL}

\section{Material and Methods}

This research used materials from E.Merck with pro analysis (p.a) quality i.e. $\mathrm{Mg}\left(\mathrm{NO}_{3}\right)_{2} \cdot 6 \mathrm{H}_{2} \mathrm{O}$, $\mathrm{Al}\left(\mathrm{NO}_{3}\right)_{3} \cdot 9 \mathrm{H}_{2} \mathrm{O}, \mathrm{HCl}, \mathrm{NaOH}, \mathrm{HNO}_{3}$ and $\mathrm{C}_{7} \mathrm{H}_{6} \mathrm{O}_{5} \cdot \mathrm{H}_{2} \mathrm{O}$ (3,4,5-trihydroxy benzoic acid/gallic acid/GA) from Sigma-Aldrich. For the preparation of the $\mathrm{Au}(\mathrm{III})$ solution was used $\mathrm{Au}$ metal from ANTAM Indonesia.

\section{General Procedure}

The synthesis of Mg/Al-HT-GA was carried out using GA of various concentrations of $0.05,0.1,0.2,0.3$, $0.5 \mathrm{M}$ and fixed molar composition of $\mathrm{Mg}$ : $\mathrm{Al}(2: 1)$ in alkaline condition $(\mathrm{pH}=10)$. The mixture was treated using a hydrothermal method at $120^{\circ} \mathrm{C}$ for 5 hours and then was cooled at room temperature. The precipitate was separated from the solution by centrifugation. The precipitate was washed with decarbonized water, filtered and dried at $70{ }^{\circ} \mathrm{C}$ for 48 hours. The adsorption of $10 \mathrm{~mL} \mathrm{Au(III)} \mathrm{of} 500$ mg. $\mathrm{L}^{-1}$ was performed by using $10 \mathrm{mg} \mathrm{Mg} / \mathrm{Al}-\mathrm{HT}-\mathrm{GA}$ at $\mathrm{pH}=3$ for 4.5 hours. After mixing $\mathrm{Au}(\mathrm{III})$ and $\mathrm{Mg} / \mathrm{Al}-\mathrm{HT}-\mathrm{GA}$, the solution was filt the solution was filtered using a Whatman paper and was dried at 70 ${ }^{\circ} \mathrm{C}$ for 6 hours.

\section{Detection Method}

The characterization of all materials from $\mathrm{Mg} / \mathrm{Al}-\mathrm{HT}-\mathrm{GA}$ was performed by using a spectrophotometer Fourier Transform Infra-Red (FTIR) (Shimadzu Prestige-21) to determine the functional group and XRay Diffraction (Shimadzu X6000) determine the crystallinity and the distance of the interlayer of $\mathrm{Mg} / \mathrm{Al}-\mathrm{HT}-\mathrm{GA}$. The residue of Au(III) was measured by using Atomic Absorption Spectroscopy (AAS) (Elmer 3110).

\section{RESULTS AND DISCUSSION}

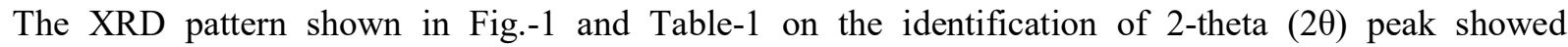
considerable differences clearly in the gallic acid intercalated $\mathrm{Mg} / \mathrm{Al} \mathrm{HT}$ depending on the variation of the molar concentration of $\mathrm{Mg}: \mathrm{Al}: \mathrm{GA}$. The greater concentration of GA caused $\mathrm{d}_{003}$ peak shift toward the smaller 2-theta. This indicates that the anion of GA has entered into the interlayers of $\mathrm{Mg} / \mathrm{Al}-\mathrm{HT}$ (interlayer of $\mathrm{Mg} / \mathrm{Al}-\mathrm{HT}$ ). The greatest shifting of $\mathrm{d}_{003}$ basal spacing occurred on gallic acid intercalated $\mathrm{Mg} / \mathrm{Al}-\mathrm{HT}$ with a molar ratio of $\mathrm{Mg}: \mathrm{Al}: \mathrm{GA}$ was $2: 1: 0.5$ and the value of $\mathrm{d}_{003}$ was $9.46 \AA$.

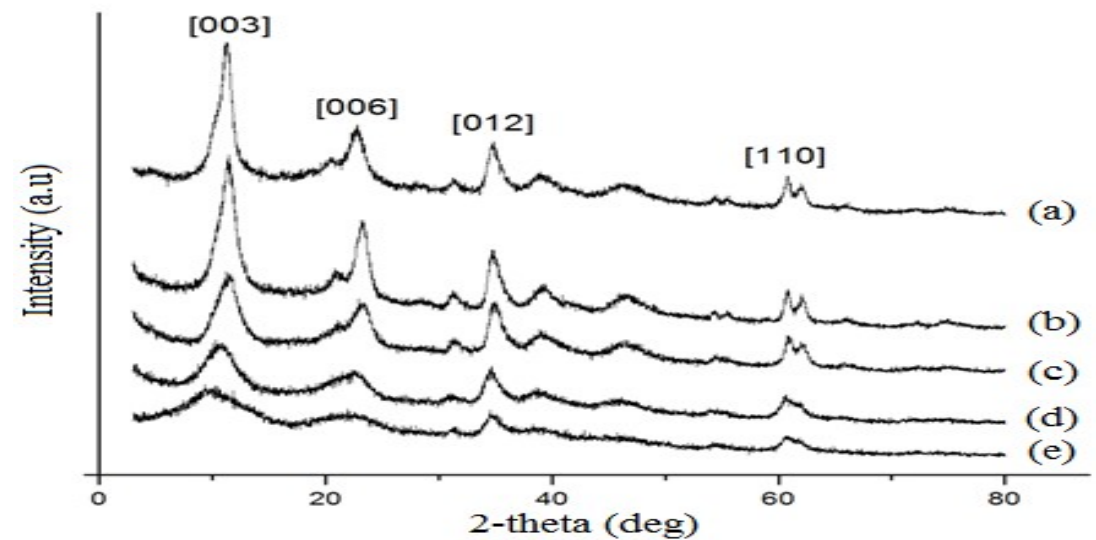

Fig.-1: XRD Pattern of Mg/Al-HT-GA at Various GA Concentration; (a) 0.05, (b) 0.1, (c) 0.2, (d) 0.3 and (e) 0.5

The result in Fig.-1 and Table-1 showed that the more AG were used for the synthesis of the gallic acid intercalated $\mathrm{Mg} / \mathrm{Al}-\mathrm{HT}$, and then anion of GA could shift the presence of $\mathrm{NO}_{3}{ }^{-}$anions in the interlayer of 
RASĀYAN J. Chem.

Vol. 13 | No. 2 |1129 - 1133| April - June | 2020

$\mathrm{Mg} / \mathrm{Al}-\mathrm{HT}$, which causes the increase in the basal spacing value of $\mathrm{d}_{003}$. The changes in the basal spacing value of $\mathrm{d}_{003}$ reached $1.51 \AA$ on the gallic acid intercalated $\mathrm{Mg} / \mathrm{Al}-\mathrm{HT}$ when the molar ratio of $\mathrm{Mg}$ : Al: GA was 2:1:0.5.

Table-1: Identification of 2-theta $\mathrm{d}_{003}$ of XRD Pattern of Mg/Al HT-GA in a Various Molar Ratio of Mg:Al: GA

\begin{tabular}{c|c|c|c}
\hline Sample & $\begin{array}{c}\text { Mole Ratio } \\
\text { (Mg:Al:GA) }\end{array}$ & $\begin{array}{c}2 \theta \\
\mathrm{d}_{003}(\mathrm{deg})\end{array}$ & $\mathrm{d}_{003}(\AA)$ \\
\hline $\mathrm{a}$ & $(2: 1: 0.05)$ & 11.12 & 7.95 \\
\hline $\mathrm{b}$ & $(2: 1: 0.1)$ & 11.29 & 7.82 \\
\hline $\mathrm{c}$ & $(2: 1: 0.2)$ & 11.29 & 7.83 \\
\hline $\mathrm{d}$ & $(2: 1: 0.3)$ & 10.66 & 8.29 \\
\hline $\mathrm{e}$ & $(2: 1: 0.5)$ & 09.34 & 9.46 \\
\hline
\end{tabular}

The results of the characterization using FTIR spectrophotometer on gallic acid (GA) intercalated Mg/AlHT, which was synthesized at the molar ratio of Mg:Al:GA, showed some differences (Fig.-2 and Table2). The declining peaks of the absorption at $1381 \mathrm{~cm}^{-1}$ with the increasing concentration of gallic acid used in the synthesis of gallic acid (GA) intercalated Mg/Al-HT (Fig.-1a to e). The absorption peak at $1381 \mathrm{~cm}^{-1}$ is assigned to vibration of the $\mathrm{N}-\mathrm{O}$ stretching of the anion $\mathrm{NO}_{3}^{-}$. This indicates that the number of $\mathrm{NO}_{3}{ }^{-}$which was replaced by GA on the HT interlayer raised. The absorption peaks at 1635 and 3464 $\mathrm{cm}^{-1}$ were due to respectively the vibration of bending and stretching of $\mathrm{O}-\mathrm{H}$ from the hydroxyl group of HT. This is due to the increased concentration of GA that could shift the presence of the hydroxyl groups on the surface layer of $\mathrm{Mg} / \mathrm{Al}-\mathrm{HT}$ and $\mathrm{H}_{2} \mathrm{O}$ molecules in the interlayers of $\mathrm{Mg} / \mathrm{Al}-\mathrm{HT}$. The new absorption peaks were observed at $1273 \mathrm{~cm}^{-1}$ which was $\mathrm{C}-\mathrm{O}$ stretching vibration of the carboxylate and the sharp peak at $2931 \mathrm{~cm}^{-1}$ was a C-H stretching vibration $\left(\mathrm{sp}^{2}\right)$ on the aromatic ring of gallic acid (GA). This phenomenon indicated that the material Mg/Al-HT has intercalated GA under the condition of the higher concentration of GA.

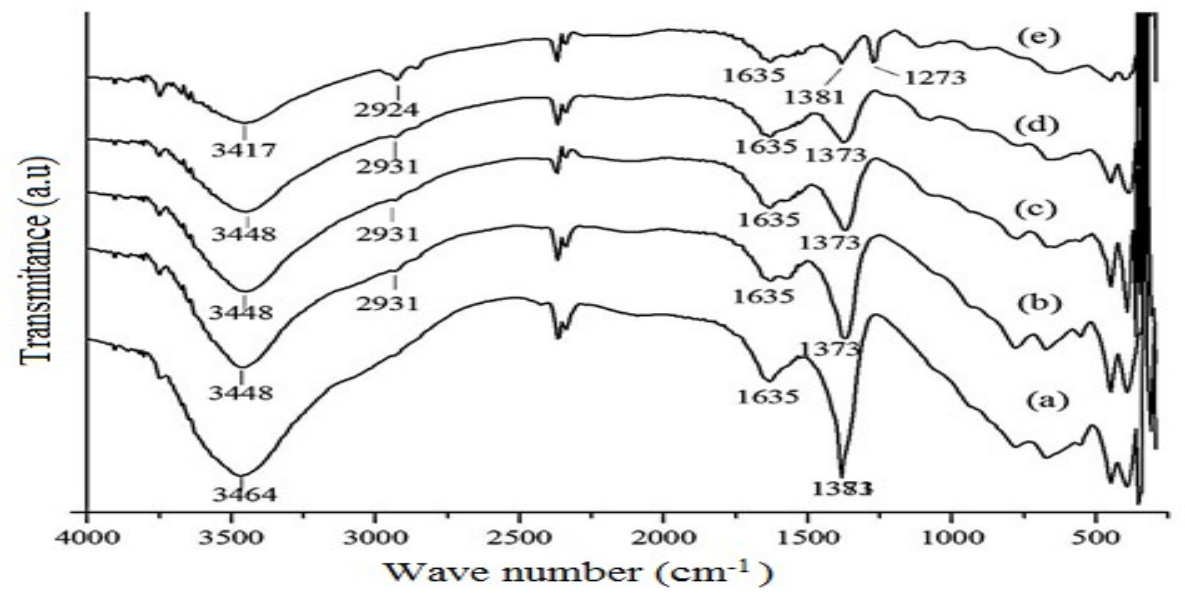

Fig.-2: FTIR Spectra of Mg/Al-HT-GA at Various Concentration of GA; (a) 0.05, (b) 0.1, (c) 0.2, (d) 0.3 and (e) 0.5

Table-2: Identification of FTIR Spectra From Gallic Acid Intercalated Mg/Al-HT at Some Molar Ratios of

Mg: Al: GA

\begin{tabular}{c|c|c|c|c|c}
\hline \multirow{2}{*}{ Characteristic Band } & \multicolumn{5}{|c}{ Wave Number $\left(\mathrm{cm}^{-1}\right)$ on the Molar Ratio of Mg:Al: GA } \\
\cline { 2 - 6 } & $2: 1: 0.05$ & $2: 1: 0.1$ & $2: 1: 0.2$ & $2: 1: 0.3$ & $2: 1: 0.5$ \\
\hline O-H stretching & 3464 & 3464 & 3448 & 3448 & 3417 \\
\hline O-H bending & 1635 & 1635 & 1635 & 1635 & 1635 \\
\hline C-H stretching $\left(\mathrm{sp}^{2}\right)$ & - & 2931 & 2931 & 2931 & 2924 \\
\hline $\mathrm{N}-\mathrm{O}$ stretching $\left(\mathrm{NO}_{3}^{-}\right)$ & 1381 & 1373 & 1373 & 1373 & 1383 \\
\hline $\mathrm{C}-\mathrm{O}$ stretching & - & - & - & - & 1273 \\
\hline $\mathrm{Mg}-\mathrm{O}-\mathrm{Al}$ vibration & $<500$ & $<500$ & $<500$ & $<500$ & $<500$ \\
\hline
\end{tabular}


The changes were reinforced by the shift of the vibration absorption peak of $\mathrm{O}-\mathrm{H}$ stretching toward the smaller wave number. This phenomenon is the same as the character of bentonite after the process of pillarization (intercalation). ${ }^{24}$ The shift was influenced by strong bonds between atoms due to the difference in electronegativity of each atom. The vibration of $\mathrm{O}-\mathrm{H}$ stretching diminished after the addition of gallic acid (GA), where previously the group O-H at HT binds with a nitrogen atom (N) of the nitrate anions $\left(\mathrm{NO}_{3}{ }^{-}\right)$. The electronegativity of $\mathrm{O}>\mathrm{N}$ causes the $\mathrm{O}-\mathrm{H}$ bonds in $\mathrm{HT}$ with the $\mathrm{O}$ atoms in gallic anions to weaken after HT binds to gallic anion. So that the energy to vibrate the O-H bond from HT is also smaller. Energy will be equivalent to the wavenumber, if the vibrational energy is low then, the wavenumber will also be smaller. Therefore, the wave number on the $\mathrm{OH}$ vibration on HT that has remembered the gallic anion will shift towards smaller wavenumbers. It was shown by Fig.-3e, i.e. $\mathrm{Mg} / \mathrm{Al}-\mathrm{HT}-\mathrm{GA}$ with a variation of the molar concentration of 2:1:0.5 (Mg:Al:GA).

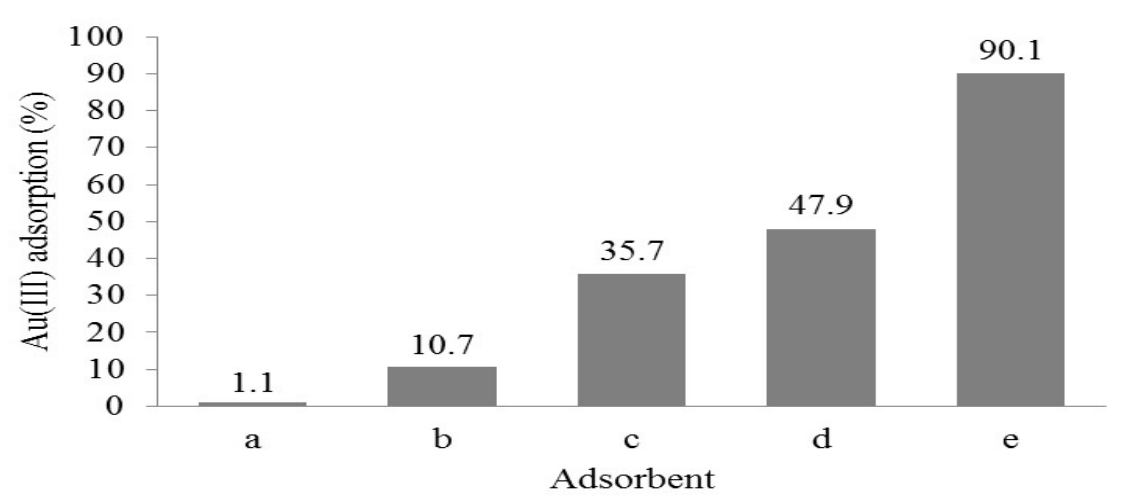

Fig.-3: The Adsorption Percentage of $10 \mathrm{~mL} \mathrm{Au(III)} 500 \mathrm{mg} . \mathrm{L}^{-1}$ by $10 \mathrm{~mL} \mathrm{Mg/Al} \mathrm{HT-GA} \mathrm{Synthesized} \mathrm{at} \mathrm{Mole}$ Ratios (Mg:Al:GA) a (2:1:0.05), b (2:1:0.1), c (2:1:0.2), d (2:1:3) and e (2:1:0.5) at pH 3 for 270 Minutes.

Figure-3 shows that the adsorption of $\mathrm{Au}(\mathrm{III})$ by the adsorbent of Mg/Al-HT-GA increased along with the increasing concentration of gallic acid used in the synthesis of gallic acid intercalated Mg/Al-HT. This was because, at $\mathrm{pH} 3, \mathrm{H}^{+}$of the gallic acid molecule will act as a hydrogen bridge between the groups with $\mathrm{Au}(\mathrm{III})$. Based on these statements it can be concluded that the greater the concentration of gallic acid (GA), the more adsorption of $\mathrm{Au}$ (III) will be increased, accompanied by the reduction of $\mathrm{Au}(\mathrm{III})$ to $\mathrm{Au}(0)$. The adsorption of $\mathrm{Au}(\mathrm{III})$ under optimum conditions has an adsorption capacity of $90.1 \%$. The optimum condition occurs at $\mathrm{Mg} / \mathrm{Al}-\mathrm{HT}-\mathrm{GA}$ with a molar ratio of $\mathrm{Mg}$ :Al: GA (2: 1: 0.5) under acidic conditions $(\mathrm{pH}=3)$ during 270 minutes.

\section{CONCLUSION}

The higher concentration of GA used in the modification of Mg/Al-HT caused the occurrence of GA intercalation on the interlayer $\mathrm{Mg} / \mathrm{Al}-\mathrm{HT}$. GA intercalation in the interlayer HT is known to increase in the basal spacing $\mathrm{d}_{003}$ in HT $(9.46 \AA)$ with a variation of Mg:Al: GA $(2: 1: 0.05)$. The higher concentration of GA could cause the replacements of $\mathrm{NO}_{3}{ }^{-}$in HT interlayer which was reduced the intensity of absorption peak at 1373-1383 $\mathrm{cm}^{-1}$ shown in FTIR spectra, the sharpness of the peak becomes be lower. The greater concentration of GA used in the HT modification causes the increase in Au adsorption capacity up to $90.1 \%$.

\section{REFERENCES}

1. F. Cavani, F. Trifari , and A. Vaccari, Catalisys Today, 11, 173(1991), DOI:10.1016/09205861(91)80068-K.

2. M. A. Ulibarri, I. Pavlovic, C. Barriga, M. C. Hermosin, J. Correjo, Applied Clay Science, 18(1-2), 17(2001), DOI:10.1016/S0169-1317(00)00026-0.

3. J. Matusik and K. Rybka, Materials, 12, 1373(2019), DOI:10.3390/ma12091373.

4. G. Rosano-Ortega, C. Lebrún, J. Oglesby, S. Gallegos, D. Cruz-González and B. Armendariz, Green and Sustainable Chemistry, 3(2), 48(2013), DOI:10.4236/gsc.2013.32009.

5. X. Tong, Z. Yang, P. Xu, Y. Li, X. Niu, Water Science and Technology, 75(9), 2194(2017), 
DOI: $10.2166 /$ wst.2017.082.

6. E. Heraldy, S. J. Santosa, Triyono, K. Wijaya, Indonesian Journal of Chemistry, 15(3), 234(2015), DOI: $10.22146 /$ ijc. 21190.

7. N. A. Ikhsan, Thesis, Department of Chemistry, Universitas Gadjah Mada, Yogyakarta, Indonesia (2011).

8. D. Fitriani, 2013, Thesis, Department of Chemistry, Universitas Gadjah Mada, Yogyakarta, Indonesia (2013).

9. T. Sulistyaningsih, S. J. Santosa, D. Siswanta and B. Rusdiarso, Indonesian Journal of Chemistry, 16(3), 268(2016), DOI:10.22146/ijc. 1149.

10. T. S. Anirudhan, S. Jalajamony, S. S. Sreekumari, Journal of Chemical and Engineering Data, 58, 24(2013), DOI:10.1021/je300536u.

11. Y. Xu, J. Zhang, G. Qian, Z. Ren, Z. P. Xu, Y. Wu, Q. Liu, S. Qiao, Industrial \& Engineering Chemistry Research, 49(6), 2752(2010).

12. I. Garcia-Sosa and M. T. Olguin, Separation Science and Technology, 50(17), 2631(2015), DOI: $10.1080 / 01496395.2015 .1066810$.

13. L. Nong, C. Xiao, W. Jiang, Korean Journal of Chemical Engineering, 28(3), 933(2011), DOI: $10.1007 / \mathrm{s} 11814-010-0447-5$.

14. Y. H. Rao and K. Ravindhranath, Rasayan Journal of Cemistry, 10(4), 1104(2017), DOI: 10.7324/RJC.2017.1041829.

15. D. Parajuli, H. Kawakita, K. Inoue, K. Ohto, K. Kajiyama, Hydrometallurgy, 87, 133(2007), DOI:10.1016/j.hydromet.2007.02.006.

16. H. Kawakita, Science and Technology, 2(1), 25(2012), DOI:10.5923/j.scit.20120201.05.

17. M. J. Lerma-Garcia, M. Avila, E. F. Simo-Alfonso, A. Rios, M. Zougagh, Journal of Materials and Environmental Science, 5(6), 1919(2014).

18. M. Ma, Y. Wei, G. Zhao, F. Liu, Y. R. Zhu, International Journal of Environmental Protection and Policy, 2(6), 230(2014), DOI:10.11648/j.ijepp.20140206.16.

19. Z. Peng, H. Zhong, Asian Journal of Chemistry, 26(12), 3605(2014), DOI:10.14233/ajchem.2014.16552.

20. Q. Q. Gong, X.Y. Guo, S. Liang, C. Wang, Q.H. Tian, International Journal of Environmental Science and Technology, 13, 47(2016), DOI:10.1007/s13762-015-0809-y.

21. K. Inoue, M. Gurung, Y. Xiong, H. Kawakita, K. Ohto, and S. Alam, Metals, 5, 1921(2015), DOI: 10.3390/met5041921.

22. S. P. Newman and W. Jones. New Journal of Chemistry, 22, 105(1998), DOI:10.1039/A708319J.

23. M. Z. Hussein, N. Hashim, A. H. Terkawalnya, Z. Zainal, Sains Malaysiana, 40(8), 887(2011).

24. T. Taher, R. Mohadi, and A. Lesbani, Rasayan Journal of Chemistry, 11(3), 1244(2018), DOI:10.31788/RJC.2018.1133065.

[RJC-5543/2019] 